\title{
Warming effects on plant biomass allocation and correlations with the soil environment in an alpine meadow, China
}

\author{
XU Manhou ${ }^{1 *}$, LIU Min ${ }^{1}$, XUE Xian ${ }^{2}$, ZHAI Datong ${ }^{1}$ \\ ${ }^{1}$ Taiyuan Normal University, Jinzhong 030619, China; \\ ${ }^{2}$ Cold and Arid Regions Environmental and Engineering Research Institute, Chinese Academy of Sciences, Lanzhou 730000, \\ China
}

\begin{abstract}
Alpine meadow ecosystem is fragile and highly sensitive to climate change. An understanding of the allocation of above- and below-ground plant biomass and correlations with environmental factors in alpine meadow ecosystem can result in better protection and effective utilization of alpine meadow vegetation. We chose an alpine meadow in the Qinghai-Tibetan Plateau of China as the study area and designed experimental warming plots using a randomized block experimental design. We used single-tube infrared radiators as warming devices, established the warming treatments, and measured plant above- (AGB) and below-ground biomass (BGB) during the growing seasons (May to September) in 2012 and 2013. We determined the allocation of biomass and the relationship between biomass and soil environment under the warming treatment. Biomass indices including above-ground biomass, below-ground biomass and the ratio of root to shoot (R/S), and soil factors including soil moisture and soil temperature at different depths were measured. The results showed that (1) BGB of the alpine meadow had the most significant allometric correlation with its AGB $\left(y=298.7 x^{0.44}, P<0.001\right)$, but the relationship decreased under warming treatment and the determination coefficient of the functional equation was 0.102 which was less than that of 0.188 of the unwarming treatment (control); (2) BGB increased, especially in the deeper soil layers under warming treatment $(P>0.05)$. At $0-10 \mathrm{~cm}$ soil depth, the percentages of BGB under warming treatment were smaller than those of the control treatment with the decreases being $8.52 \%$ and $8.23 \%$ in 2012 and 2013 , respectively. However, the BGB increased $2.13 \%$ and $2.06 \%$ in 2012 and 2013, respectively, at 10-50 cm soil depths; (3) BGB had significant positive correlations with soil moisture at $100 \mathrm{~cm}$ depth and with soil temperature at $20-100 \mathrm{~cm}$ depths $(P<0.05)$, but the mean correlation coefficient of soil temperature was 0.354 , greater than the 0.245 of soil moisture. R/S ratio had a significant negative correlation with soil temperature at $20 \mathrm{~cm}$ depth $(P<0.05)$. The warmer soil temperatures in shallow layers increased the biomass allocation to above-ground plant parts, which leading to the increase in AGB; whereas the enhanced thawing of frozen soil in deep layers causing by warming treatment produced more moisture that affected plant biomass allocation.
\end{abstract}

Keywords: alpine meadow; above-ground biomass; below-ground biomass; soil environment; warming

Citation: XU Manhou, LIU Min, XUE Xian, ZHAI Datong. 2016. Warming effects on plant biomass allocation and correlations with the soil environment in an alpine meadow, China. Journal of Arid Land, 8(5): 773-786. doi: $10.1007 / \mathrm{s} 40333-016-0013-\mathrm{z}$

\footnotetext{
*Corresponding author: XU Manhou (E-mail: xumanhou@163.com)

Received 2015-10-31; revised 2016-04-08; accepted 2016-04-23

(C) Xinjiang Institute of Ecology and Geography, Chinese Academy of Sciences, Science Press and Springer-Verlag Berlin Heidelberg 2016
} 
Grassland is one of the most widely distributed ecosystems in the world and plays an important role in the global carbon cycle and in climate regulation (Xia et al., 2014). Grassland biomass reflects energy flow, material flow and primary production, and is an indicator of the functional strength of the grassland community and ecosystem (Carlyle et al., 2014; Hovenden et al., 2014; Xia et al., 2014; Dusseux et al., 2015). Accurate measurement of grassland biomass and the correlations between above- and below-ground biomass and environments are significant for evaluating the source and sink functions of $\mathrm{CO}_{2}$ and predicting the relationship between grassland ecosystems and global climate change (Hovenden et al., 2014; Xia et al., 2014).

Allocation of above- and below-ground biomass reflects plant survival strategy, which affects individual plant growth and vegetation structure, as well as the grassland soil carbon inputs and the terrestrial ecosystem carbon cycle (Litton et al., 2007; Hovenden et al., 2014). The ratio of root to shoot biomass $(\mathrm{R} / \mathrm{S})$ is an important parameter in most terrestrial ecosystem carbon cycle models. However, precise determination of $\mathrm{R} / \mathrm{S}$ remains difficult due to the difficulties involved in root sampling (Yang et al., 2010). The research of Ni (2004) with emphasis on above- and below-ground biomass allocation found the changes from individual species scale to a community scale in the grassland ecosystems of China. On a community scale, above- and below-ground biomass allocation in grasslands is consistent with the isometry in the Qinghai-Tibetan Plateau (QTP), and the R/S ratio showed no significant trends with annual mean temperature or annual precipitation (Fan et al., 2009; Yang et al., 2009, 2010). However, we found that, due to the large differences among environments, especially the large difference between ground and air temperature, the $\mathrm{R} / \mathrm{S}$ ratio conformed to the allometric allocation in an alpine meadow of the QTP at the same scale (Xu and Xue, 2013). Thus, the relationship of R/S with environmental factors remains unclear in grassland ecosystems at the community scale.

Correlations between biomass allocation and environment parameters in grassland ecosystems have been intensively studied (Alfaro-Sánchez et al., 2015; Cunniff et al., 2015; Freschet et al., 2015; Gong et al., 2015; Ichihashi and Tateno, 2015; Modrzyński et al., 2015; Pallas and Christophe, 2015; Sellin et al., 2015; Tanis et al., 2015; Wang et al., 2015). However, we found several problems through analyzing these researches (Yang et al., 2009, 2010), which include: (1) differences in study methods and data sources can significantly affect results; (2) inventory data or published biomass data of grassland resources are typically used, but the measured data in field are often lacking in unified field surveys; and (3) above-ground biomass is clearly influenced by precipitation, whereas the responses of below-ground biomass to environmental factors are more complicated. Accurate and detailed surveys are therefore still needed in these same study areas. The goal of the research is to illustrate the allocation of above- and below-ground biomass and its correlation with environmental factors, especially the increased temperatures associated with global climate change.

Global climate change can involve greater variability of both temperature and precipitation. The QTP is sensitive and vulnerable to climate change, and is regarded as the third pole of the world and the Chinese water tower. The QTP has strong effects on the climate change, the water cycle and the ecology of environments on regional and global scales through its powerful dynamic and thermodynamic influences. The QTP is an ideal region to study the responses of a terrestrial ecosystem to global climate change (Li et al., 2011; Shi et al., 2012). The QTP is also a vital region of the global cryosphere, where permafrost is widely distributed (Pang et al., 2009). The permafrost environment is very sensitive to climate change, and the alpine grassland ecosystem is especially fragile in this region (Wang and Wu, 2013). Meteorological data from 1971 to 2000 showed that the mean temperature has increased at a rate of $0.032^{\circ} \mathrm{C} / \mathrm{a}$ in the QTP (Liu and Chen, 2000). Thus, the QTP climate is experiencing a warming trend which is causing significant changes of soil and vegetation (Zhang, 2007; Yang et al., 2010).

The QTP extends over an area of $2.5 \times 10^{6} \mathrm{~km}^{2}$ (Xue et al., 2014). Alpine meadow ecosystems cover about $35 \%$ of the QTP area and comprise the representative vegetation and the major pasture land in the QTP (Xue et al., 2014). Alpine meadow is a typical QTP vegetation type but is special, which is adapted to the high elevation and low-temperature environment, with vegetation types typical of high plateaus and mountains (Peng et al., 2015). Alpine meadow ecosystems are fragile 
and sensitive to human disturbance and climate change (Peng et al., 2014). Once disturbed, these meadows do not recover quickly, and will be often further degradation or desertification (Wang and $\mathrm{Wu}, 2013$; You et al., 2014). Research on biomass has been hindered in the QTP by its harsh climate and environmental conditions. Additional problems have included shortcomings in methodology, destructive sampling and heavy emphasis on root analysis. Therefore, detailed studies on the sensitivity of alpine meadow biomass to climate change are urgently needed in the QTP.

For studying the changes of above- and below-ground biomass and the correlation between biomass and the environment, we used single-tube infrared radiators as warming devices and carried out simulated warming experiments, starting in 2010, in a QTP alpine meadow. We asked the following questions: (1) what is the correlation between above- and below-ground biomass allocation and does the biomass allocation change under warming treatments? and (2) what is the relationship between biomass and the environment and how does the relationship change under warming treatments?

\section{Study area and methods}

\subsection{Study area}

The study area is located on the Beiluhe Observation Station of Frozen Soil Environment and

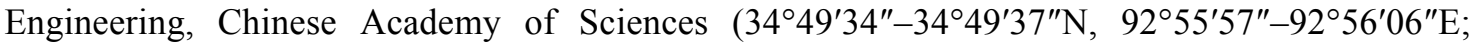
4,633.5 m; Fig. 1a) (Xu et al., 2014, 2015). The site is in an arid and cold area of the QTP with an annual mean temperature of $-5.9^{\circ} \mathrm{C}$, a mean annual precipitation of $267.6 \mathrm{~mm}$, a mean annual potential evaporation of $1,316.9 \mathrm{~mm}$ and an annual mean wind speed of $4.1 \mathrm{~m} / \mathrm{s}$. The frozen period lasts for 7-8 months from September to April next year. The depths of frozen soil generally range from 2 to $3 \mathrm{~m}$ with a maximum of $3.4 \mathrm{~m}$ and a minimum of $1.7 \mathrm{~m}$. The vegetation at this site belongs to the typical alpine meadow with Kobresia pygmaea as the dominant species as well as significant compositions of Leontopodium nanum, Saussurea pulchra, Kobresia tibetica, Carex moorcroftii and Oxytropis pusilla. The species of Cyperus and Compositae account for a large proportion of the vegetation composition and Polygonum viviparum (Polygonaceae) is also common. In total, the vegetation cover reaches $83 \%$. The soil type at the site belongs to the alpine meadow soil with the thickness of mattic epipedon $5-15 \mathrm{~cm}$ and the content of soil organic matter $8-25 \mathrm{~g} / \mathrm{kg}$.

\subsection{Experimental design}

The experiment was designed as a randomized block with five sub-blocks and four treatments per sub-blocks (Fig. 1b) (Xu et al., 2014, 2015). We chose the control and warming plots to study warming effects on the allocation of above- and below-ground biomass. Control plots were not exposed to warming and the warming plots were irradiated by heaters with a radiative flux of 130 $\mathrm{W} / \mathrm{m}^{2}$ for $24 \mathrm{~h}$ starting in July 2010 and the power density was adjusted to $150 \mathrm{~W} / \mathrm{m}^{2}$ in October 2011. At the time of data sampling in September 2013, simulated warming had been continuously applied for 3 years.

In the warming plots, single-tube infrared radiators (Kalglo Electronics, Bethlehem, PA, USA) were used as the heaters to simulate enhanced downward infrared radiation mimicking anthropogenic warming. The irradiance spectrum of the radiator showed very little energy being emitted below $850 \mathrm{~nm}$, so it was regarded as photochromatically inactive. As such, the plants did not respond photosynthetically and only responded to the warmth of the radiant energy (Kimball, 2005). Therefore, this spectrum was considered to be suitable for the warming treatment in the alpine ecosystem. The reflector surface of the radiator was suspended at $1.5 \mathrm{~m}$ above the warmed plots and was modified to distribute the radiation evenly over the soil surface (Kimball, 2005). This ensured that the heat generated by the radiator was relatively even over the entire surface area of each warmed plot and the treatment was similar at different soil depths (Wan et al., 2002). Unlike most typical warming experiments focused on either summer or winter warming, the heating in this experiment was provided during the entire year. 


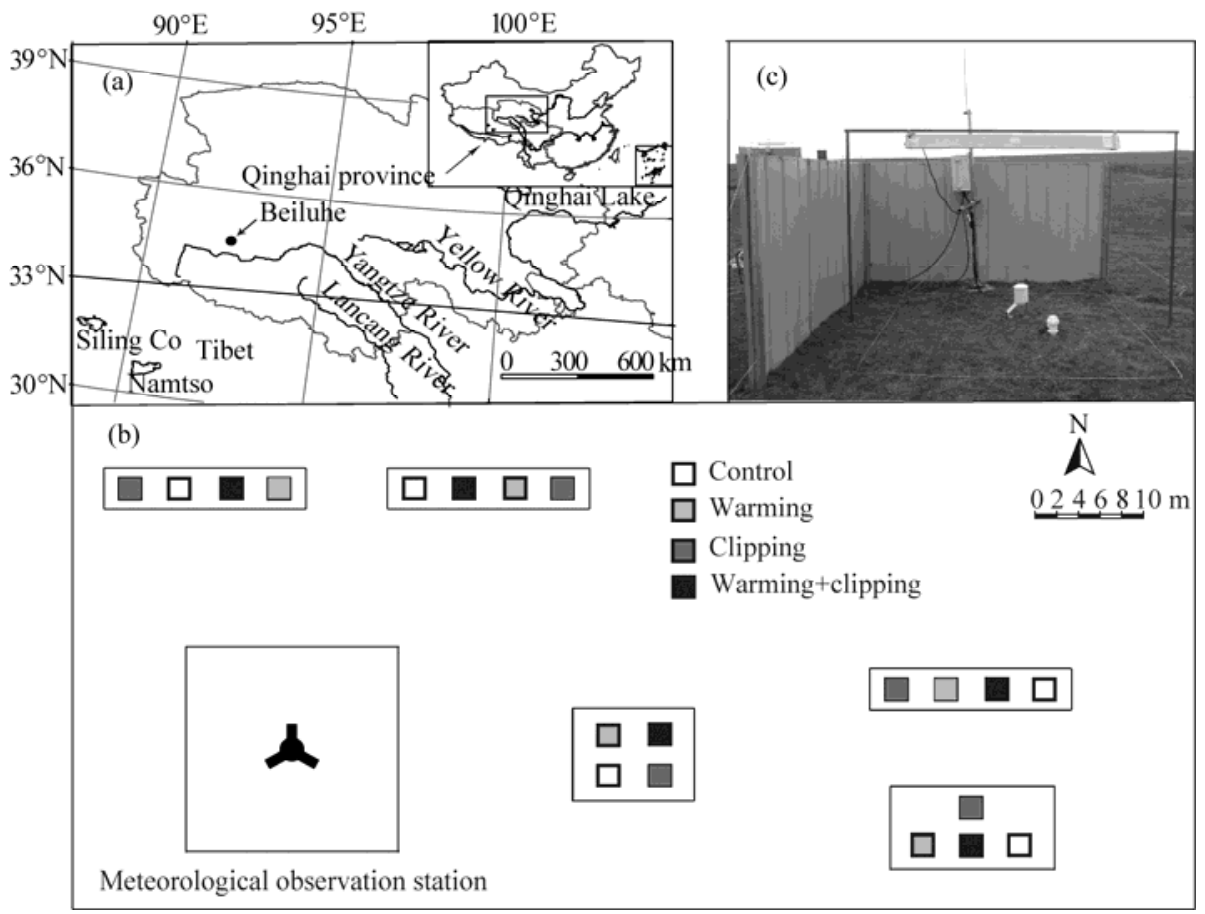

Fig. 1 Location of the study site (a), experimental design (b) and experimental plot with instrument (c)

In the control plots, each plot had a dummy radiator (without a heating element) of the same dimension as infrared radiators and suspended at a similar height to keep shading effects of the radiator consistent in all of the plots (Xue et al., 2011). For reducing the effects of wind on the experiments, we designed two steel windshields, $1.5 \mathrm{~m}$ high, located at the northern and western points in all plots based on the dominant wind direction from the west and installed at a distance $1.5 \mathrm{~m}$ from the center of the plots. A permanent meteorological observation station was set up at a 4-m height outside the plots to record climate data.

\subsection{Temperature and moisture measurements}

Temperature and moisture were measured in experimental plots beginning July 2010 (Xu et al., 2014). The data reported here covered the period from May to September during 2012 and 2013. Temperature measurements were taken at soil depths of 20, 40, 60 and $100 \mathrm{~cm}$. Moisture measurements were soil moisture at 20,40,60 and $100 \mathrm{~cm}$ depths. Temperature probes were installed in soil to measure the soil temperature at depths of 20, 40, 60 and $100 \mathrm{~cm}$. Frequency Domain Reflectometry (FDR) moisture probes were placed in soil to measure soil moisture at depths of 20, 40, 60 and $100 \mathrm{~cm}$. These data were automatically recorded every 10 min by a Campbell Scientific data logger and the data used for this research were averaged daily. These probes and loggers (Campbell Scientific Inc., USA) were set up inside the experimental plots (Fig. 1c).

\subsection{Plant biomass measurement}

Plants and soil were not destroyed in the experimental plots so plant above-ground biomass (AGB) was not obtained directly by clipping. For sampling AGB, we established 100 additional temporary plots with an area of $20 \mathrm{~cm} \times 20 \mathrm{~cm}$ or $30 \mathrm{~cm} \times 30 \mathrm{~cm}$ (unwarmed) that shared similar habitat, plant height and plant cover with the neighboring experimental plots. Within these plots we destructively harvested plant AGB from May 2010 to September 2013 (Xu et al., 2015). Using these data, a stepwise regression equation (see data analyses) was established using plant AGB, height, cover and species number in the temporary plots to indirectly obtain the plant AGB during different periods in the experimental plots.

Plant below-ground biomass (BGB) was sampled using a soil corer with an internal diameter of 
$7 \mathrm{~cm}$ (Xu et al., 2015). One core with no replication was extracted every $10 \mathrm{~cm}$ between 0 and 50 $\mathrm{cm}$ depths in the center of each experimental plot during the growing season (May to September) in 2012 and 2013, respectively. Five cores were respectively obtained under the control and warming plots, providing 5 soil layers $(0-10,10-20,20-30,30-40$ and 40-50 cm) and 25 soil samples. After roots and soil were extracted, they were immediately placed in a cooler and transported to the laboratory. In the laboratory, soil samples were air-dried and crumbled by hand to pass through a 2-mm diameter sieve to remove large particles. Then, roots were separated from the soil samples and filtered with a $0.25-\mathrm{mm}$ sieve to retrieve fine roots. Live roots were distinguished from dead roots by color, consistency and presence of attached fine roots. The above-ground plants and live roots were put into an oven to dry for $48 \mathrm{~h}$ to constant weight at $75^{\circ} \mathrm{C}$, and then weighed.

\subsection{Data analyses}

The stepwise regression equation was established via SPSS 16.0 software (SPSS Inc., Chicago, USA) among plant AGB, height, cover and species number in the temporary plots (Xu et al., 2015).

$$
a b=308.26 c+22.764 h-121.801\left(R^{2}=0.737, P<0.001, n=100\right) .
$$

Where $a b$ is the plant AGB $\left(\mathrm{g} / \mathrm{m}^{2}\right), c$ is the plant cover (fractional representation) and $h$ is the plant height $(\mathrm{cm})$. From the equation, plant AGB was estimated by plant height and plant cover measurements.

Ratio of root to shoot $(\mathrm{R} / \mathrm{S})$ was calculated by the ratio of total $\mathrm{BGB}$ in the $0-50 \mathrm{~cm}$ layers to AGB. Total BGB was obtained by summing the BGB in 5 soil layers and bar graphs of BGB were drawn with Origin 8.0 software (Origin Lab., Northampton, MA, USA) in different months for analyzing changes of BGB over months in the growing season. Then, mean BGB was calculated among 5 months in each soil layer and percentages of BGB were calculated by the ratio of BGB in each soil layer to total BGB. The bar graphs of BGB percentages were drawn with the Origin 8.0 software in different soil layers for analyzing the trends of vertical distribution of BGB. Significance tests of BGB were conducted by one-way ANOVA or multi-way ANOVA in the SPSS 16.0 software between months, soil depths, treatments and their interactions.

Regression equations were established via the SPSS 16.0 software between BGB and depths in the 5 soil layers, and then BGB was deduced in the 50-60 cm soil layer. BGB was defined as zero if BGB was negative in the 50-60 cm soil layer, which showed BGB being limited to the $0-50 \mathrm{~cm}$ soil layers. We chose soil moisture and temperature at 20,40 and $60 \mathrm{~cm}$ depths based on the distribution depths of roots $(0-60 \mathrm{~cm})$ in order to analyze the relationship of BGB with the corresponding soil moisture and temperature using the Origin 8.0 software in the same soil layers. The dependent variables were BGB in the soil layers of 10-20, 30-40 and 50-60 cm.

\section{Results}

\subsection{Changes of BGB in different months and soil depths}

BGB differed in 2012 and 2013 (Fig. 2). In 2012, BGB seasonally increased and was greater from July to September with an average of $3,810.88$ and $4,468.08 \mathrm{~g} / \mathrm{m}^{2}$ under the control and warming treatments, respectively. In 2013, BGB seasonally decreased and was greater from May to June with an average of $4,175.39$ and $4,141.6 \mathrm{~g} / \mathrm{m}^{2}$ under the control and warming treatments, respectively. From May to September, BGB was greater under warming than that of control treatment with the difference being 482.41 and $105.52 \mathrm{~g} / \mathrm{m}^{2}$ in 2012 and 2013 , respectively. The differences of BGB were not significant between warming and control treatments in different months $(P>0.05)$. BGB slightly increased under the warming treatment, but the increased levels differed among months, and thus resulted in variable levels of inter-annual BGB.

BGB was mainly distributed at $0-10 \mathrm{~cm}$ depth with the percentages of the total being $49.57 \%$ and 51.65\% in 2012 and 2013, respectively (Fig. 2). The BGB allocation had larger differences at different soil depths under warming treatment. At $0-10 \mathrm{~cm}$ depth, the percentages of BGB were 
smaller under the warming treatment than that of the control treatment with the decreases being $8.52 \%$ and $8.23 \%$ in 2012 and 2013 , respectively. At 10-50 cm depths, the percentages of BGB were greater under warming treatment than that of the control with the increases being $2.13 \%$ and $2.06 \%$ in 2012 and 2013, respectively. The warming treatment led to changes in the vertical distribution of BGB in soil. However, the results of multi-way ANOVA of BGB showed that BGB differences between treatments were not significant $(P>0.05)$, whereas there were significant differences between soil depths $(P<0.001)$ (Table 1). The proportions of BGB tended to occur in deeper soil layers under warming treatment indicating that warming resulted in downward movement of roots in the alpine meadow soil.
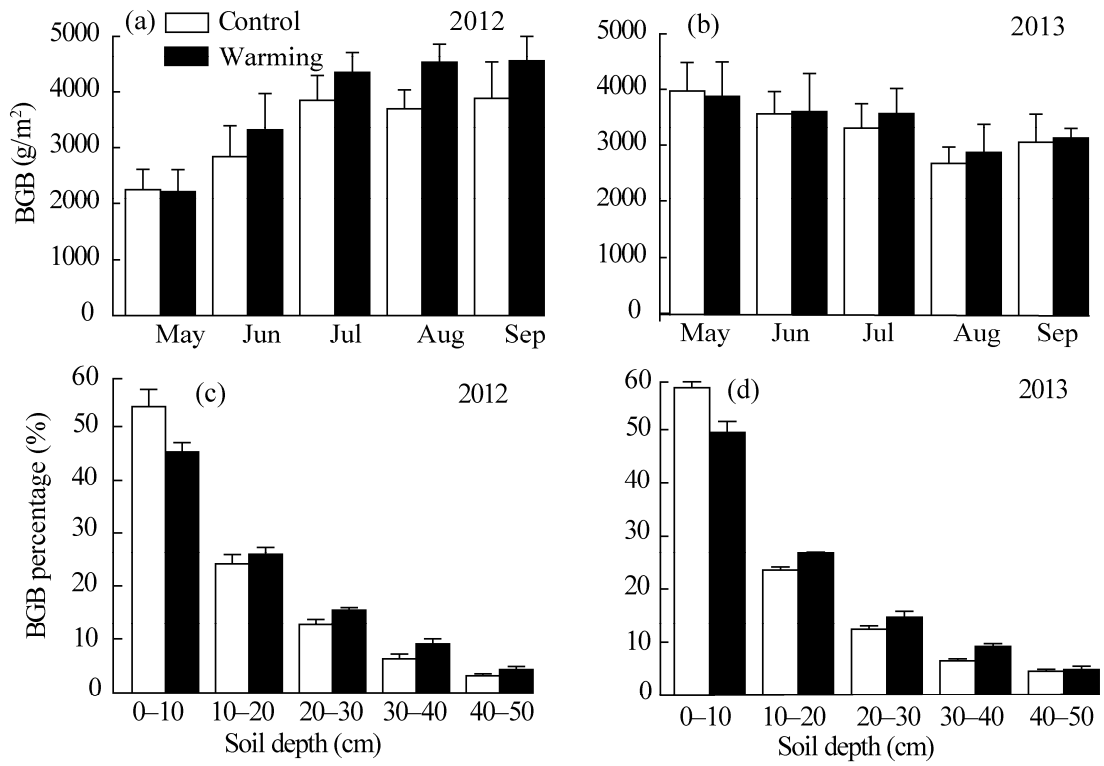

Fig. 2 Below-ground biomass (BGB; a and b) in different months and the distribution of BGB in different soil layers ( $\mathrm{c}$ and d) under the control and warming treatments in 2012 and 2013. BGB of 5 soil layers were summed in each month and BGB percentages of 5 months were averaged in each soil layer, so the number was 5 with months and soil layers, respectively.

Table 1 The multi-way ANOVA of root biomass basing on general linear model

\begin{tabular}{|c|c|c|c|c|c|c|}
\hline \multirow{2}{*}{ Item } & \multicolumn{2}{|c|}{ BGB } & \multicolumn{2}{|c|}{ BGB percentage } & \multicolumn{2}{|c|}{ Total BGB } \\
\hline & 2012 & 2013 & 2012 & 2013 & 2012 & 2013 \\
\hline Treatment & $5.073^{*}$ & 0.008 & 0 & 0 & 2.409 & 0.004 \\
\hline Month & $13.038^{* * *}$ & 2.102 & 0 & 0 & $6.192^{* * *}$ & 1.752 \\
\hline Depth & $163.824^{* * *}$ & $163.501^{* * *}$ & $401.212^{* * *}$ & $416.577^{* * *}$ & - & - \\
\hline Treatment $\times$ month & 0.448 & 0.125 & 0 & 0 & 0.213 & 0.071 \\
\hline Treatment $\times$ depth & 1.470 & $3.212^{*}$ & $6.887^{* * *}$ & $6.272^{* * *}$ & - & - \\
\hline Month $\times$ depth & 1.290 & 0.487 & $2.408^{* *}$ & 0.657 & - & - \\
\hline Treatment $\times$ month $\times$ depth & 0.369 & 0.173 & 0.828 & 0.461 & - & - \\
\hline
\end{tabular}

Note: BGB, below-ground biomass; ${ }^{*},{ }^{* *}$ and ${ }^{* * *}$ indicate significance at $P<0.05, P<0.01$ and $P<0.001$ levels, respectively; 0 and indicate that this item is not conducted and existed in analysis, respectively.

\subsection{Correlation between BGB and AGB}

BGB and AGB had a highly significant correlation of power exponent function by curve fitting $\left(y=298.7 x^{0.44}, P<0.001, n=80\right.$; Fig. 3$)$. Where, the power exponent function was highly significant 
under the control $\left(y=260.8 x^{0.46}, P<0.01, n=40\right)$ and was significant under warming treatment $\left(y=389.2 x^{0.397}, P<0.05, n=40\right)$. The determination coefficient of the functional equation was slightly lower under the warming treatment, which was 0.102 and less than the 0.188 of the control treatment. The log-transformed biomass was used to conduct linear correlation analysis (Fig. 3). The correlation was highly significant under the control treatment $(P<0.01)$ and was significant under warming treatment $(P<0.05)$. Warming weakened the correlation between $\mathrm{BGB}$ and AGB with the intercept being slightly increased and the slope being slightly decreased in the linear equation. The slopes of all linear equations were less than 1 under the warming and control treatments, so an allometric correlation existed in BGB and AGB. However, the allometric correlation between BGB and AGB under warming treatment was less.
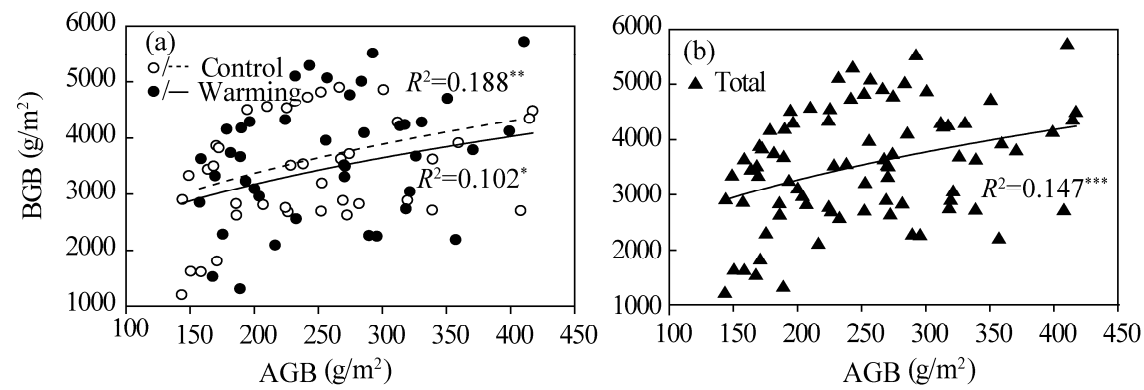

Fig. 3 Curve fit between above-ground biomass and below-ground biomass under control and warming treatments. AGB, above-ground biomass; BGB, below-ground biomass; the data were from 4 plots in each month in 2012 and 2013, respectively. The number was 40 in the control and warming treatments and 80 in total, respectively. ${ }^{*}{ }^{* *}$ and $^{* * *}$ indicate significance at $P<0.05, P<0.01$ and $P<0.001$ levels, respectively.

\subsection{Effects of soil environment on biomass at different soil depths}

Soil moisture increased and soil temperature decreased with increasing soil depth under both control and warming treatments. Relative to the control, the increasing and decreasing amplitudes were all greater under the warming treatment $(\mathrm{Xu}$ et al., 2015; Fig. 4). Thus, warming had increased soil moisture in deeper soil layers and temperature in upper soil layers.

Regression correlations between biomass and soil temperature and moisture at different depths showed that AGB had a significant positive correlation with soil moisture at $60-100 \mathrm{~cm}$ depths and with soil temperature at $20-100 \mathrm{~cm}$ depths $(P<0.05$; Fig. 5). For soil moisture, the correlation was highly significant at the $100 \mathrm{~cm}$ depth with a correlation coefficient of $0.423(P<0.01)$ and was significant at $60 \mathrm{~cm}$ depth with a correlation coefficient of $0.223(P<0.05)$. For soil temperature, the correlation was significant at $100 \mathrm{~cm}$ depth $(P<0.05)$ and highly significant at 20-60 cm depths $(P<0.01)$. The correlation coefficients of soil temperature decreased with depths and the mean was 0.46 , which was greater than 0.323 of the correlation coefficient of soil moisture.

BGB had a significant positive correlation with soil moisture at $100 \mathrm{~cm}$ depth and with soil temperature at $20-100 \mathrm{~cm}$ depths $(P<0.05$; Fig. 5). The correlation was significant with soil moisture at $100 \mathrm{~cm}$ depth $(P<0.05)$ and highly significant with soil temperature at $20-100 \mathrm{~cm}$ depths $(P<0.01)$. The correlation coefficients of soil temperature increased with depths and the mean was 0.354 , which was greater than 0.245 of the correlation coefficient of soil moisture.

$\mathrm{R} / \mathrm{S}$ had a significant negative correlation with soil temperature at $20 \mathrm{~cm}$ depth $\left(R^{2}=-0.238\right.$, $P<0.05$; Fig. 5). AGB was more influenced by soil moisture in the deep layers and by soil temperature in the shallow layers, whereas BGB was more influenced by soil moisture and temperature in the deep layers. Soil temperature in shallow layers affected biomass allocation and promoted biomass of the above-ground parts and thus increased AGB. The effects of soil temperature were greater than that of soil moisture on AGB and BGB. 


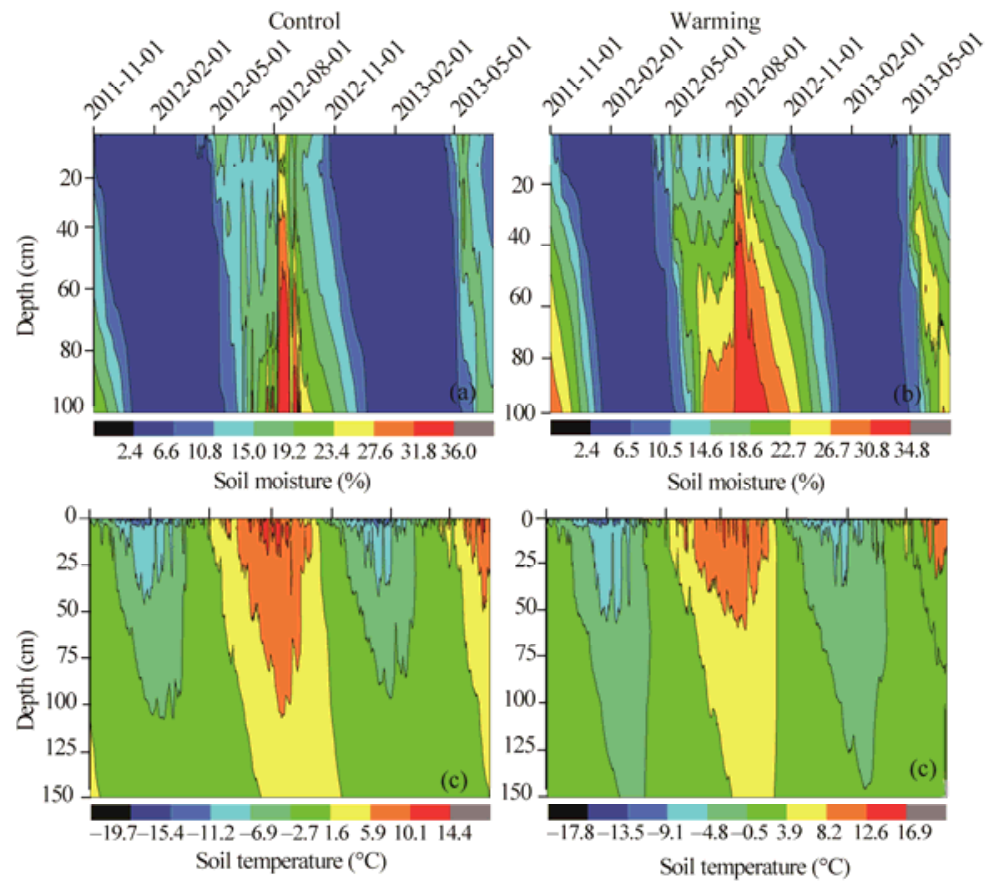

Fig. 4 Trends of soil moisture and temperature with dates and depths under the control and warming treatments
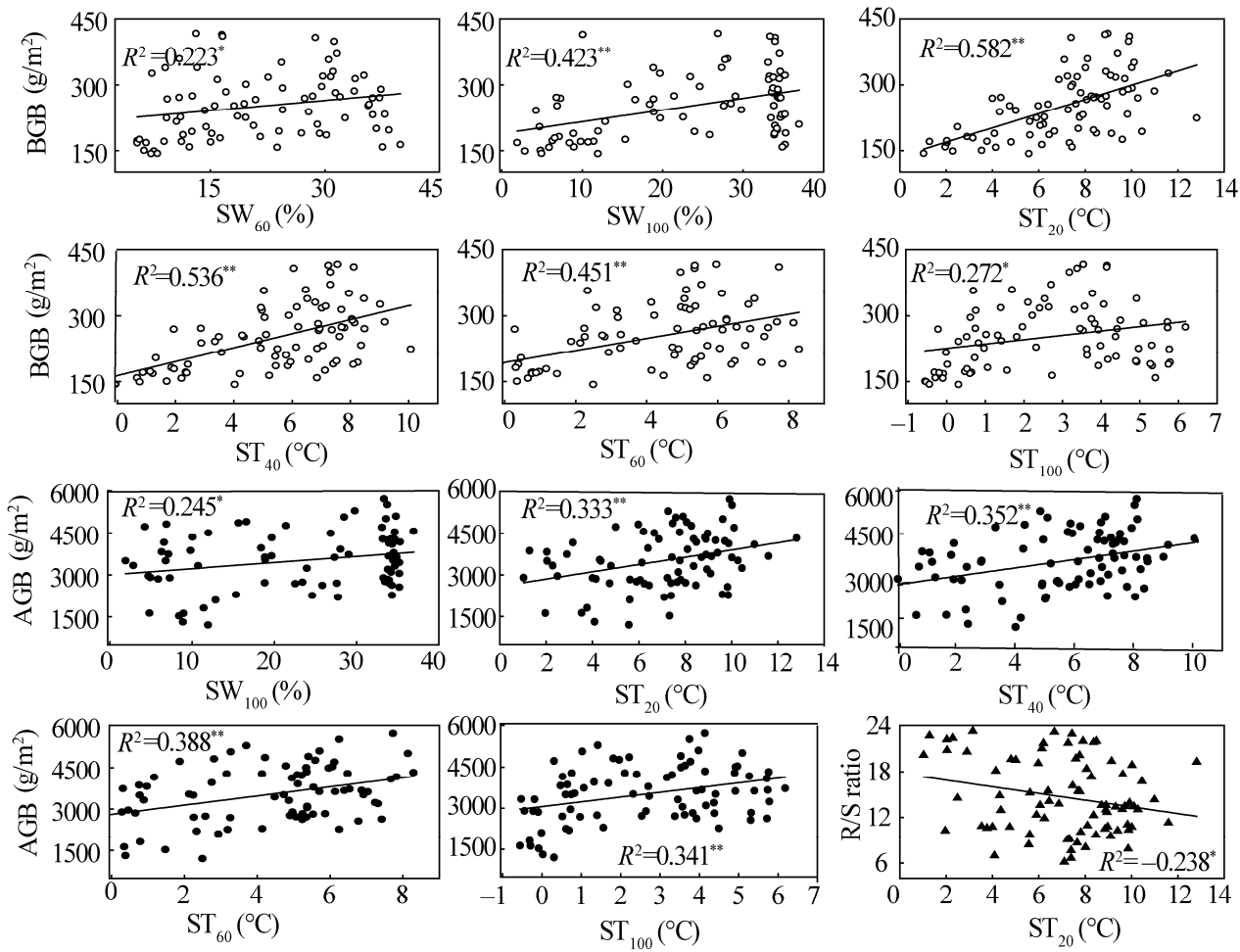

Fig. 5 Linear correlation between biomass and soil moisture and temperature at different soil depths. BGB, below-ground biomass; $\mathrm{AGB}$, above-ground biomass; $\mathrm{R} / \mathrm{S}$, root:shoot ratio; $\mathrm{SW}_{60}$ and $\mathrm{SW}_{100}$, soil moistures at 60 and $100 \mathrm{~cm}$ depths, respectively; $\mathrm{ST}_{20}, \mathrm{ST}_{40}, \mathrm{ST}_{60}$ and $\mathrm{ST}_{100}$, soil temperatures at $20,40,60$ and $100 \mathrm{~cm}$ depths, respectively; ${ }^{*}$ and ${ }^{* *}$ indicate significance at $P<0.05$ and $P<0.01$ levels, respectively. The data were from 8 plots in each month in 2012 and 2013. The total number was 80 . 


\subsection{Effects of soil environment on BGB}

BGB had a highly significant negative relationship with soil moisture in corresponding soil layers $(P<0.01$; Fig. 6). The absolute value of the regression equation slope increased, the determination coefficient slightly decreased, and the significance value increased under warming treatment. Warming weakened the relationship between BGB and soil moisture. BGB had highly significant positive relationship with soil temperature in corresponding soil layers $(P<0.01$; Fig. 6$)$. The slope of the regression equation increased, the determination coefficient slightly increased, and the significant value decreased under warming treatment. Warming therefore enhanced the linear progressive relationship between BGB and soil temperature. Furthermore, the regression slope of BGB was greater with soil temperature than that with soil moisture and the difference was 20.67 (Fig. 6). Therefore, both soil moisture and soil temperature had highly significant influences on $\mathrm{BGB}$, but the effects of soil temperature on BGB were obvious under warming treatment.

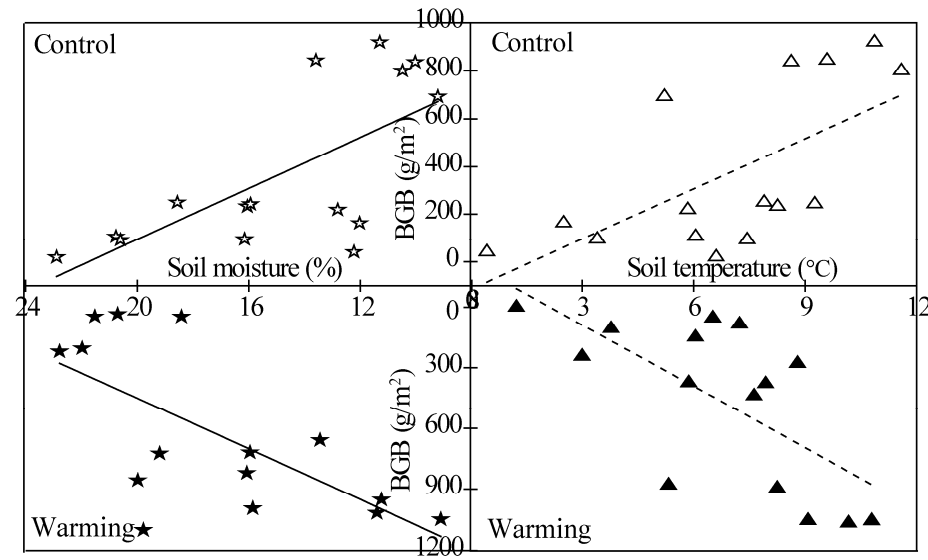

Fig. 6 Linear regression correlation between below-ground biomass (BGB) and soil moisture and temperature in corresponding soil layers. The data were from 3 layers $(10-20,30-40$ and $50-60 \mathrm{~cm})$ in each month and were averaged in 2012 and 2013. The total number is 15.

\section{Discussion}

\subsection{Allocation of AGB and BGB}

The allometric law, usually expressed using a power exponent function, is not only used to describe the nonlinear relationship between body size and other biological properties, but also to demonstrate the relationship between the sizes of two different organs or two different properties (West et al., 1997, 1999a, b). We generated curve fits to study the correlation between AGB and $\mathrm{BGB}$, and found that $\mathrm{AGB}$ and $\mathrm{BGB}$ had a highly significant correlation of the power exponent function $\left(y=298.7 x^{0.44}, P<0.001, n=80\right)$ with the slope of the linear equation being much less than 1 after $\log$ transformation. Therefore, an allometric correlation exists between AGB and BGB. Previous research also showed that above- and below-ground plant parts in alpine meadow had different growth patterns, presumably due to the large differences between their environments $(\mathrm{Xu}$ and $\mathrm{Xu}, 2013)$. The above-ground parts approximated the pattern of isometry with the power exponent of 1.011 and the below-ground parts showed a pattern of allometry with the power exponent of 0.459 . The whole plant exhibited an allometric pattern with the power exponent of 0.473 (Xu and Xu, 2013). Our conclusions differed from the results of Yang et al. (2009, 2010). Although a highly significant power exponent function $\left(R^{2}=0.56, P<0.001\right)$ was found in AGB and BGB in a grassland of China, the linear correlation slope in an alpine meadow was 0.940 after logarithmic transformation. Therefore, the allocation of AGB and BGB conformed to the isometric theory in the alpine meadow of Qinghai-Tibet. We concluded that the results on AGB and BGB allocation had larger discrepancies due to different study scales, sampling methods and plant types. 
AGB was accurately estimated due to mature and intact target plants but estimation of BGB was subject to greater error due to roots lost during sampling (Yang et al., 2009, 2010). Dead roots and live roots were distinguished by their color and morphology, but differentiation was extremely difficult because of the numerous plant species involved and the diverse colors and morphology of roots in grassland community (Yang et al., 2009, 2010). These two issues made accurate BGB measurement difficult. Our research did not support the isometric theory and this might be related to plant growth features in the study area. The fractal structure of alpine meadow plants was not as clear as woody plants in the Qinghai-Tibet. A great many perennial herbs were rosette plants with their stems functioning as support structures for reproductive organs, rather than transporting nutrients to leaves. In addition, some plant underground parts did not absorb nutrients and water, but were storage structures, such as tubers, earthnuts or rhizomes. As a result, many alpine meadow plants did not conform the theoretical assumption by Enquist and Niklas (2002) who concluded that plant stems and roots had proportional growth. For this reason, when studying the allocation of AGB and BGB, additional surveys at the same site and plant type are needed to clarify possible biomass discrepancies caused by different scales.

\subsection{Correlation between biomass allocation and the environment}

Plant biomass allocation is primarily influenced by climate. Plants alter their biomass allocation in different organs to improve their ability to efficiently absorb nutrients under changing environmental conditions (Yang et al., 2009, 2010). The R/S ratio of a global grassland ecosystem had significant negative correlations with annual temperature and precipitation (Mokany et al., 2006), while the R/S ratio in grasslands of China showed no obvious correlations (Yang et al., 2009, 2010). Therefore, the heterogeneity of environmental factors had an important impact on plant biomass allocation (Hollingsworth et al., 2008; Kokfelt et al., 2009; Yuan and Chen, 2010).

Temperature controls many biochemical reaction rates in ecosystems and affects essentially all biological processes (Gutiérrez and Jones, 2006). Temperature supplies the energy required by plants for normal growth, modifies the micro-environments of plant communities and directly or indirectly affects the production and allocation of plant biomass via multiple channels (Aerts, 2006; Gutiérrez and Jones, 2006). In our 1-year warming experiment, above-ground plants were directly affected by the soil moisture at 40-60 $\mathrm{cm}$ depths, whereas below-ground plants were directly affected by soil temperature at $40 \mathrm{~cm}$ depth and soil moisture at $60 \mathrm{~cm}$ depth. This demonstrated that deep soil temperatures and moisture can influence the growth of alpine meadow plants $\mathrm{Xu}$ et al., 2014). The results from our 3-year warming experiment illustrated that AGB was more strongly influenced by soil moisture in deep layers and soil temperature in shallow layers, whereas BGB was more strongly influenced by soil moisture and temperatures in the deep layers. In this study, the effects of soil temperatures were greater than soil moisture on AGB and BGB. These results might be influenced by variations in the level and distribution of soil moisture, temperature and other elements caused by the melting of frozen soil under warming treatment (Xu et al., 2014). At the end of the 3-year warming study, there was less soil moisture under the control treatment than that of the warming treatment at $60-100 \mathrm{~cm}$ depths, and the soil moisture differences between the control and warming treatments were reduced at 10-20 cm depths but greater at $60-100 \mathrm{~cm}$ depths (Xu et al., 2015). Therefore, warming caused melting of frozen soil in the alpine meadow ecosystem.

Warming directly affected plants by raising temperatures and indirectly influenced plants by modifying soil moisture. De Boeck et al. (2007) found that AGB and BGB decreased by $18 \%$ and $23 \%$, respectively, due to the reduction of soil moisture induced by warming. Xu et al. (2014) found that warming decreased below-ground net primary productivity in a tallgrass prairie. AGB and BGB were both influenced by temperature but limited by soil moisture. With moisture limitation plants tend to allocate more biomass to roots (Yin et al., 2008) while the allocation models were influenced by many other factors including increasing temperature. In a 65-month warming experiment, warming increased stem biomass, decreased leaf biomass, but did not significantly affect root biomass, illustrating that long-term warming promoted more biomass allocation to stems (Yang et al., 2010). In a 10-month warming experiment, warming promoted more biomass allocation to roots under full light conditions, whereas it promoted more biomass allocation to 
leaves under low light conditions (Yin et al., 2008). Our study showed that temperatures in shallow soil affected biomass allocation and induced more biomass allocation to above-ground plant parts, whereas deep soil moisture affected plant biomass allocation due to the thawing of frozen soil under warming treatment. The plant biomass allocation responses to warming were affected by soil moisture and light and were also related to the duration of warming.

\subsection{Relationship between BGB and the soil environment}

BGB in the alpine meadow was primarily $(50.61 \%$ of total) distributed in the $0-10 \mathrm{~cm}$ soil layer. Under the warming treatment, BGB was reduced by $8.38 \%$ in the $0-10 \mathrm{~cm}$ layer but increased by $2.1 \%$ in the $10-50 \mathrm{~cm}$ layer. BGB had an overall increase under warming treatment and the increase was greater in the deeper soil layers. Similarly, Li et al. (2011) found that a relatively low temperature $\left(2.59^{\circ} \mathrm{C}\right)$ increased $\mathrm{BGB}$ in the $0-5 \mathrm{~cm}$ root zone in an alpine meadow; after a relatively high temperature $\left(5.16^{\circ} \mathrm{C}\right)$, BGB was distributed in deeper root zones due to soil moisture restrictions. The relative air humidity at $20 \mathrm{~cm}$ height was stable but increased moisture was detected in deeper soil layers in our warming plots and the increase was greater at $150 \mathrm{~W} / \mathrm{m}^{2}$ than at $130 \mathrm{~W} / \mathrm{m}^{2}$ (Xu et al., 2014). Soil moisture is transported to deeper layers under warming treatment. Increasing soil moisture in the deeper layers is most likely derived from downward water transport due to the weak water retaining capacity of the coarse-textured sandy soils (Xue et al., 2014). Similarly, Yang et al. (2003) reported that soil moisture increased with soil depth in the Tibetan Plateau and this increase was related to freezing-thaw processes and temperature distribution. We found that soil temperature was higher in upper soil layers while soil moisture increased in deeper layers (Xu et al., 2015). The increased soil moisture in deeper layers might induce the downward movement of BGB to these layers. We reported that the downward movement of BGB was closely related to the transport of soil moisture, organic carbon, active carbon and total nitrogen (Xu et al., 2015). In general, the allocation of plant BGB to deeper soil layers was clearly related to the downward movement of soil moisture.

The long-term warming experiments showed that changes in plant BGB were mostly correlated with soil moisture. For example, warming caused reduction of BGB in the $0-30 \mathrm{~cm}$ soil layers, which was associated with a decline of soil moisture (Shi et al., 2008). The drought caused by warming at the soil surface hindered root growth in shallow soil layers (Dubrovsky et al., 1998). Warming increased the death of roots and thus decreased root quantity and aggregation (Edwards et al., 2004). We found that soil moisture and temperature had highly significant effects on BGB, but the influences of soil temperature were greater and more rapid under warming treatment. This is because alpine meadow ecosystems in the study area are permafrost habitats where soil and plants are normally greatly influenced by low soil temperature. We conducted plant surveys and soil sampling during the May to September growing season when the temperatures were higher than other months. During the growing season, some of the permafrost melted and the depth of active soil layers increased. Also during this period, soil organic carbon and other nutrients can migrate to deeper soil with the soil water, and the allocation of soil organic carbon may be transferred from shallow to deeper layers (Li et al., 2011). We found that warming could transport organic carbon, activated carbon and total nitrogen from shallow to deeper layers in the soil, and this was associated with the downward allocation of plant BGB to deeper soil layers (Xu et al., 2015). Hence, variations of soil temperature were greater and more rapid than soil moisture under warming treatment. This is due to the melted permafrost water and the effect of this moisture on plant roots.

\section{Conclusions}

BGB was primarily distributed in the $0-10 \mathrm{~cm}$ layer where it contributed $50.61 \%$ of the total. Under warming treatment, $\mathrm{BGB}$ was reduced by $8.38 \%$ in the $0-10 \mathrm{~cm}$ layer but increased by $2.10 \%$ in the $10-50 \mathrm{~cm}$ layers. Therefore, BGB increased under warming treatment especially in the deep soil layers, but the increased levels varied among the months of the growing season, creating discrepancies between years. The relationship of BGB to soil moisture was negative and weak under the warming treatment whereas the BGB relationship to soil temperature was positive. Soil moisture and temperature had significant effects on BGB, but the influences of soil 
temperature were greater and more rapid under warming treatment. Soil temperature in shallow layers induced more biomass allocated to above-ground plant growth and thus increased AGB, whereas soil moisture in deep soil layers affected plant biomass due to the thawing of the frozen soil under warming treatment.

\section{Acknowledgments}

This study was funded by the National Natural Science Foundation of China (41501219). The authors thank Dr. PENG Fei, Dr. YOU Quangang, Prof. LIU Yongzhi and all of the staff at the Beiluhe Observation Station of Frozen Soil Environment and Engineering, Chinese Academy of Sciences for their help in the field. We thank many lab members for their help in measuring and collecting the environment and vegetation data. The authors also greatly thank LetPub (www.letpub.com) for its linguistic assistance during the preparation of this manuscript.

\section{References}

Aerts R. 2006. The freezer defrosting: global warming and litter decomposition rates in cold biomes. Journal of Ecology, 94(4): 713-724.

Alfaro-Sánchez R, López-Serrano F R, Rubio E, et al. 2015. Response of biomass allocation patterns to thinning in Pinus halepensis differs under dry and semiarid Mediterranean climates. Annals of Forest Science, 72(5): 595-607.

Carlyle C N, Fraser L H, Turkington R. 2014. Response of grassland biomass production to simulated climate change and clipping along an elevation gradient. Oecologia, 174(3): 1065-1073.

Cunniff J, Purdy S J, Barraclough T J P, et al. 2015. High yielding biomass genotypes of willow (Salix spp.) show differences in below ground biomass allocation. Biomass and Bioenergy, 80: 114-127.

De Boeck H J, Lemmens C H H M, Gielen H, et al. 2007. Combined effects of climate warming and plant diversity loss on above- and below-ground grassland productivity. Environmental and Experimental Botany, 60(1): 95-104.

Dubrovsky J G, North G B, Nobel P S. 1998. Root growth, developmental changes in the apex, and hydraulic conductivity for Opuntia ficus-indica during drought. New Phytologist, 138(1): 75-82.

Dusseux P, Hubert-Moy L, Corpetti T, et al. 2015. Evaluation of SPOT imagery for the estimation of grassland biomass. International Journal of Applied Earth Observation and Geoinformation, 38: 72-77.

Edwards E J, Benham D G, Marland L A, et al. 2004. Root production is determined by radiation flux in a temperate grass land community. Global Change Biology, 10(2): 209-227.

Enquist B J, Niklas K J. 2002. Global allocation rules for patterns of biomass partitioning in seed plants. Science, 295(5559): $1517-1520$.

Fan J W, Wang K, Harris W, et al. 2009. Allocation of vegetation biomass across a climate-related gradient in the grasslands of Inner Mongolia. Journal of Arid Environments, 73(4-5): 521-528.

Freschet G T, Kichenin E, Wardle D A. 2015. Explaining within-community variation in plant biomass allocation: a balance between organ biomass and morphology above vs below ground? Journal of Vegetation Science, 26(3): 431-440.

Gong X Y, Fanselow N, Dittert K, et al. 2015. Response of primary production and biomass allocation to nitrogen and water supplementation along a grazing intensity gradient in semiarid grassland. European Journal of Agronomy, 63: 27-35.

Gutiérrez J L, Jones C G. 2006. Physical ecosystem engineers as agents of biogeochemical heterogeneity. BioScience, 56(3): $227-236$.

Hollingsworth T N, Schuur E A G, Chapin III F S, et al. 2008. Plant community composition as a predictor of regional soil carbon storage in Alaskan boreal black spruce ecosystems. Ecosystems, 11(4): 629-642.

Hovenden M J, Newton P C D, Wills K E. 2014. Seasonal not annual rainfall determines grassland biomass response to carbon dioxide. Nature, 511(7511): 583-586.

Ichihashi R, Tateno M. 2015. Biomass allocation and long-term growth patterns of temperate lianas in comparison with trees. New Phytologist, 207(3): 604-612.

Kimball B A. 2005. Theory and performance of an infrared heater for ecosystem warming. Global Change Biology, 11(11): 2041-2056.

Kokfelt U, Rosén P, Schoning K, et al. 2009. Ecosystem responses to increased precipitation and permafrost decay in subarctic Sweden inferred from peat and lake sediments. Global Change Biology, 15(7): 1652-1663.

Li N, Wang G X, Yang Y, et al. 2011a. Plant production, and carbon and nitrogen source pools, are strongly intensified by experimental warming in alpine ecosystems in the Qinghai-Tibet Plateau. Soil Biology and Biochemistry, 43(5): $942-953$. 
Li N, Wang G X, Yang Y, et al. 2011b. Short-term effects of temperature enhancement on community structure and biomass of alpine meadow in the Qinghai-Tibet Plateau. Acta Ecologica Sinica, 31(4): 895-905. (in Chinese)

Litton C M, Raich J W, Ryan M G. 2007. Carbon allocation in forest ecosystems. Global Change Biology, 13(10): $2089-2109$.

Liu X D, Chen B D. 2000. Climatic warming in the Tibetan Plateau during recent decades. International Journal of Climatology, 20(14): 1729-1742.

Modrzyński J, Chmura D J, Tjoelker M G. 2015. Seedling growth and biomass allocation in relation to leaf habit and shade tolerance among 10 temperate tree species. Tree Physiology, 35(8): 879-893.

Mokany K, Raison R J, Prokushkin A S. 2006. Critical analysis of root: shoot ratios in terrestrial biomes. Global Change Biology, 12(1): 84-96.

Ni J. 2004. Estimating net primary productivity of grasslands from field biomass measurements in temperate northern China. Plant Ecology, 174(2): 217-234.

Pallas B, Christophe A. 2015. Relationships between biomass allocation, axis organogenesis and organ expansion under shading and water deficit conditions in grapevine. Functional Plant Biology, 42(12): 1116-1128.

Pang Q Q, Cheng G D, Li S X, et al. 2009. Active layer thickness calculation over the Qinghai-Tibet Plateau. Cold Regions Science and Technology, 57(1): 23-28.

Peng F, You Q G, Xu M H, et al. 2014. Effects of warming and clipping on ecosystem carbon fluxes across two hydrologically contrasting years in an alpine meadow of the Qinghai-Tibet Plateau. PLoS ONE, 9(10): e109319.

Peng F, You Q G, Xu M H, et al. 2015. Effects of experimental warming on soil respiration and its components in an alpine meadow in the permafrost region of the Qinghai-Tibet Plateau. European Journal of Soil Science, 66(1): $145-154$.

Sellin A, Rosenvald K, Õnapuu-Pikas E, et al. 2015. Elevated air humidity affects hydraulic traits and tree size but not biomass allocation in young silver birches (Betula pendula). Frontiers in Plant Science, 6: 860.

Shi F S, Wu N, Luo P. 2008. Effect of temperature enhancement on community structure and biomass of subalpine meadow in Northwestern Sichuan. Acta Ecologica Sinica, 28(11): 5286-5293. (in Chinese)

Shi F S, Chen H, Chen H F, et al. 2012. The combined effects of warming and drying suppress $\mathrm{CO}_{2}$ and $\mathrm{N}_{2} \mathrm{O}$ emission rates in an alpine meadow of the eastern Tibetan Plateau. Ecological Research, 27(4): 725-733.

Tanis S R, McCullough D G, Cregg B M. 2015. Effects of paclobutrazol and fertilizer on the physiology, growth and biomass allocation of three Fraxinus species. Urban Forestry \& Urban Greening, 14(3): 590-598.

Wan S, Luo Y, Wallace L L. 2002. Changes in microclimate induced by experimental warming and clipping in tallgrass prairie. Global Change Biology, 8(8): 754-768.

Wang J F, Wu Q B. 2013. Impact of experimental warming on soil temperature and moisture of the shallow active layer of wet meadows on the Qinghai-Tibet Plateau. Cold Regions Science and Technology, 90-91: 1-8.

Wang Y, Xi B Y, Bloomberg M, et al. 2015. Response of diameter growth, biomass allocation and $\mathrm{N}$ uptake to $\mathrm{N}$ fertigation in a triploid Populus tomentosa plantation in the North China Plain: ontogenetic shift does not exclude plasticity. European Journal of Forest Research, 134(5): 889-898.

West G B, Brown J H, Enquist B J. 1997. A general model for the origin of allometric scaling laws in biology. Science, 276(5309): 122-126.

West G B, Brown J H, Enquist B J. 1999a. The fourth dimension of life: Fractal geometry and allometric scaling of organisms. Science, 284(5420): 1677-1679.

West G B, Brown J H, Enquist B J. 1999b. A general model for the structure and allometry of plant vascular systems. Nature, 400(6745): 664-667.

Xia J Z, Liu S G, Liang S L, et al. 2014. Spatio-temporal patterns and climate variables controlling of biomass carbon stock of global grassland ecosystems from 1982 to 2006. Remote Sensing, 6(3): 1783-1802.

Xu M H, Xue X. 2013. A research on summer vegetation characteristics \& short-time responses to experimental warming of alpine meadow in the Qinghai-Tibetan Plateau. Acta Ecologica Sinica, 33(7): 2071-2083. (in Chinese)

Xu M H, Peng F, You Q G, et al. 2014. Initial effects of experimental warming on temperature, moisture, and vegetation characteristics in an alpine meadow on the Qinghai-Tibetan Plateau. Polish Journal of Ecology, 62(3): 491-509.

Xu M H, Peng F, You Q G, et al. 2015. Year-round warming and autumnal clipping lead to downward transport of root biomass, carbon and total nitrogen in soil of an alpine meadow. Environmental and Experimental Botany, 109: 54-62.

Xu X, Luo Y Q, Shi Z, et al. 2014. Consistent proportional increments in responses of belowground net primary productivity to long-term warming and clipping at various soil depths in a tallgrass prairie. Oecologia, 174(3): 1045-1054.

Xue X, Luo Y Q, Zhou X H, et al. 2011. Climate warming increases soil erosion, carbon and nitrogen loss with biofuel feedstock harvest in tallgrass prairie. GCB Bioenergy, 3(3): 198-207.

Xue X, Xu M H, You Q G, et al. 2014. Influence of experimental warming on heat and water fluxes of alpine meadows in the 
Qinghai-Tibet Plateau. Arctic, Antarctic, and Alpine Research, 46(2): 441-458.

Yang B, Wang J C, Zhang Y B. 2010. Effect of long-term warming on growth and biomass allocation of Abies faxoniana seedlings. Acta Ecologica Sinica, 30(21): 5994-6000. (in Chinese)

Yang M X, Yao T D, Gou X H, et al. 2003. The soil moisture distribution, thawing-freezing processes and their effects on the seasonal transition on the Qinghai-Xizang (Tibetan) plateau. Journal of Asian Earth Sciences, 21(5): 457-465.

Yang M X, Nelson F E, Shiklomanov N I, et al. 2010. Permafrost degradation and its environmental effects on the Tibetan Plateau: A review of recent research. Earth-Science Reviews, 103(1-2): 31-44.

Yang Y H, Fang J Y, Ji C J, et al. 2009. Above- and belowground biomass allocation in Tibetan grasslands. Journal of Vegetation Science, 20(1): 177-184.

Yang Y H, Fang J Y, Ma W H, et al. 2010. Large-scale pattern of biomass partitioning across China's grasslands. Global Ecology and Biogeography, 19(2): 268-277.

Yin H J, Liu Q, Lai T. 2008. Warming effects on growth and physiology in the seedlings of the two conifers Picea asperata and Abies faxoniana under two contrasting light conditions. Ecological Research, 23(2): 459-469.

You Q G, Xue X, Peng F, et al. 2014. Comparison of ecosystem characteristics between degraded and intact alpine meadow in the Qinghai-Tibetan Plateau, China. Ecological Engineering, 71: 133-143.

Yuan Z Y, Chen H Y H. 2010. Fine root biomass, production, turnover rates, and nutrient contents in boreal forest ecosystems in relation to species, climate, fertility, and stand age: literature review and meta-analyses. Critical Reviews in Plant Sciences, 29(4): 204-221.

Zhang T J. 2007. Perspectives on environmental study of response to climatic and land cover/land use change over the Qinghai-Tibetan Plateau: an introduction. Arctic, Antarctic, and Alpine Research, 39(4): 631-634. 